\title{
Hanford Meteorological
} Station Computer Codes

Volume 6 - The SFC Computer Code

\author{
G. L. Andrews \\ J. W. Buck
}

November 1987

Prepared for the U.S. Department of Energy under Contract DE-AC06-76RLO 1830

Pacific Northwest Laboratory Operated for the U.S. Department of Energy by Battelle Memorial Institute 


\section{DISCLAIMER}

This report was prepared as an account of work sponsored by an agency of the United States Government. Neither the United States Government nor any agency thereof, nor Battelle Memorial Institute, nor any of their employees, makes any warranty, expressed or implied, or assumes any legal liability or responsibility for the accuracy, completeness, or usefulness of any information, apparatus, product, or process disclosed, or represents that its use would not infringe privately owned rights. Reference herein to any specific commercial product, process, or service by trade name, trademark, manufacturer, or otherwise, does not necessarily constitute or imply its endorsement, recommendation, or favoring by the United States Government of any agency thereof, or Battelle Memorial Institute. The views and opinions of authors expressed herein do not necessarly state or reflect those of the United States Government or any agency thereof, or Battelle Memorial Institute.

\section{PACIFIC NORTHWEST LABORATORY operated by BATTELLE MEMORIAL INSTITUTE for the UNITED STATES DEPARTMENT OF ENERGY under Contract DE-ACO6-76RLO 1830}

\begin{tabular}{|c|c|}
\hline \multicolumn{2}{|c|}{ Printed in the United States of America } \\
\hline \multicolumn{2}{|c|}{ Available from } \\
\hline \multirow{2}{*}{\multicolumn{2}{|c|}{$\begin{array}{l}\text { National Technical Information Service } \\
\text { United States Department of Commerce }\end{array}$}} \\
\hline & \\
\hline \multicolumn{2}{|c|}{5285 Port Royal Road } \\
\hline \multicolumn{2}{|c|}{ Springfield, Virginia 22161} \\
\hline \multicolumn{2}{|c|}{$\begin{array}{l}\text { NTIS Price Codes } \\
\text { Microfiche } A 01\end{array}$} \\
\hline \multicolumn{2}{|c|}{ Printed Copy } \\
\hline & Price \\
\hline Pages & Codes \\
\hline $001-025$ & $\mathrm{~A} 02$ \\
\hline $026-050$ & $\mathrm{~A} 03$ \\
\hline $051-075$ & A04 \\
\hline $076-100$ & A05 \\
\hline $101-125$ & A06 \\
\hline $126-150$ & $\mathrm{~A} 07$ \\
\hline $151-175$ & $\mathrm{~A} 0 \mathrm{~B}$ \\
\hline $176-200$ & $\mathrm{~A} 09$ \\
\hline $201-225$ & A010 \\
\hline $226-250$ & A011 \\
\hline $251-275$ & $\mathrm{~A} 012$ \\
\hline $276-300$ & $A 013$ \\
\hline
\end{tabular}


HANFORD METEOROLOGICAL STATION COMPUTER CODES

Volume 6 - The SFC Computer Code

G. L. Andrews

J. W. Buck

November 1987

Prepared for the U.S. Department of Energy under Contract DE-AC06-76RLO 1830

Pacific Northwest Laboratory

Richland, Washington 99352 


\section{PREFACE}

This volume is the sixth in a series of volumes that describe computer programs routinely used at the Hanford Meteorological Station (HMS) (e.g., data entry programs). Each volume, which documents one computer code, consists of a program overview, user's guide, description of input, a detailed program description and flowchart, and a source listing of the code.

The first seven volumes present the data entry programs used at the HMS for archiving and checking various types of data. All of these programs use a data entry form to facilitate data input, and each code calls the same series of subroutines that control and display the data entry form at the user's terminal. The subroutines were generated from the program FORMEDIT, which was developed by John Wiberg of the Computer Science staff in the Engineering Physics Department at Pacific Northwest Laboratory. An informal user's guide to the FORMEDIT program that describes how to create, modify, and eliminate data entry forms is available from the HMS system manager. 


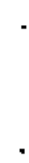




\section{SUMMARY}

Each hour the Hanford Meteorological Station (HMS), operated by Pacific Northwest Laboratory, records and archives weather observations. Hourly surface weather observations consist of weather phenomena such as cloud type and coverage; dry bulb, wet bulb, and dew point temperatures; relative humidity; atmospheric pressure; and wind speed and direction. The SFC computer code is used to archive those weather observations and apply quality assurance checks to the data. This code accesses an input file, which contains the previous archive's date and hour and an output file, which contains surface observations for the current day. As part of the program, a data entry form consisting of 24 fields must be filled in. The information on the form is appended to the daily file, which provides an archive for the hourly surface observations. 



\section{ACKNOWLEDGMENTS}

The authors would like to thank the staff at the Manford Meteorological Station for their assistance during the preparation of this document. Special thanks to the HMS Project Manager Dana Hoitink for his continued support and Van Ramsdell for his helpful suggestions and ideas. 



\section{CONTENTS}

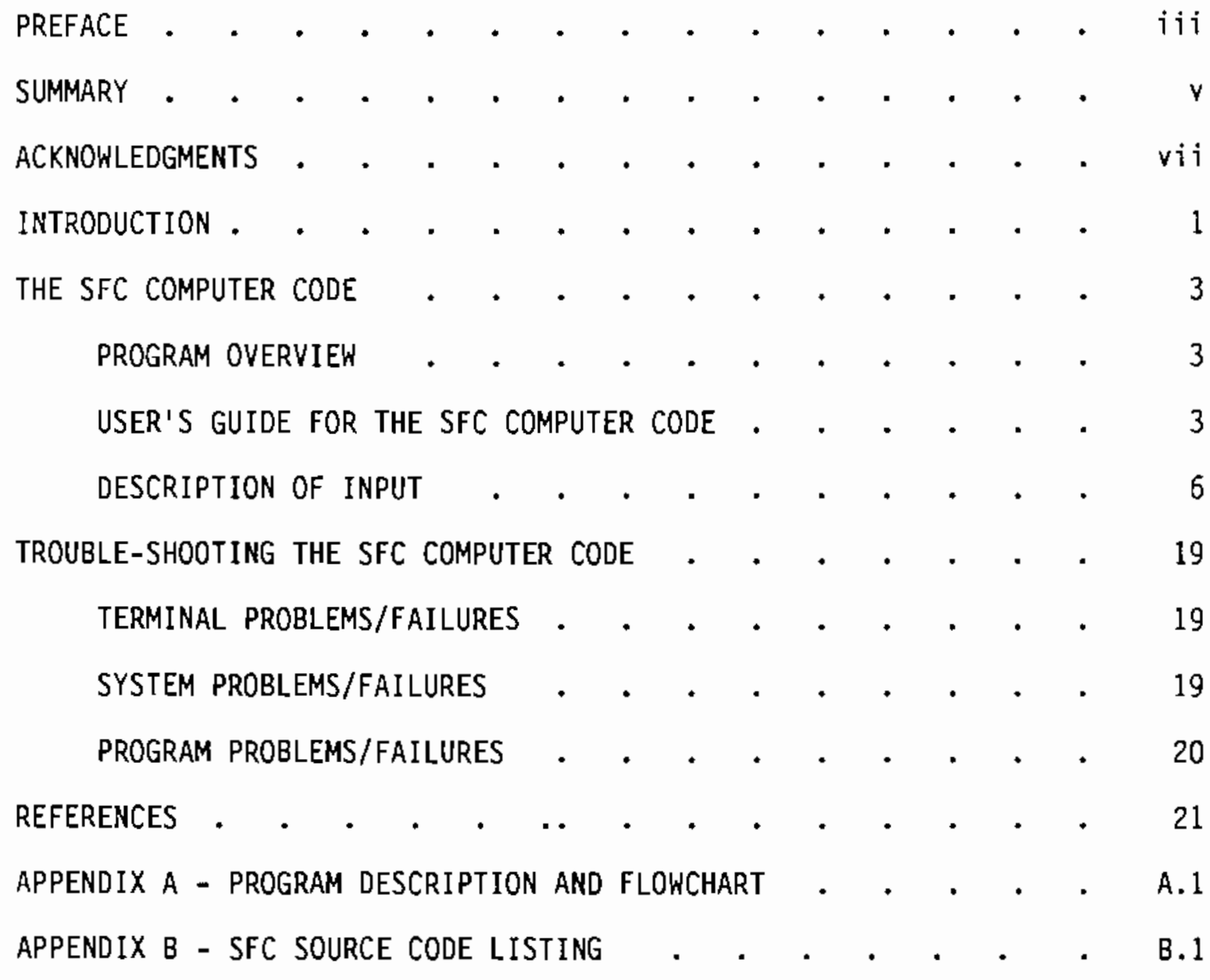


FIGURE

1 Example of the Data Entry Form Used by the SFC Computer Code

TABLES

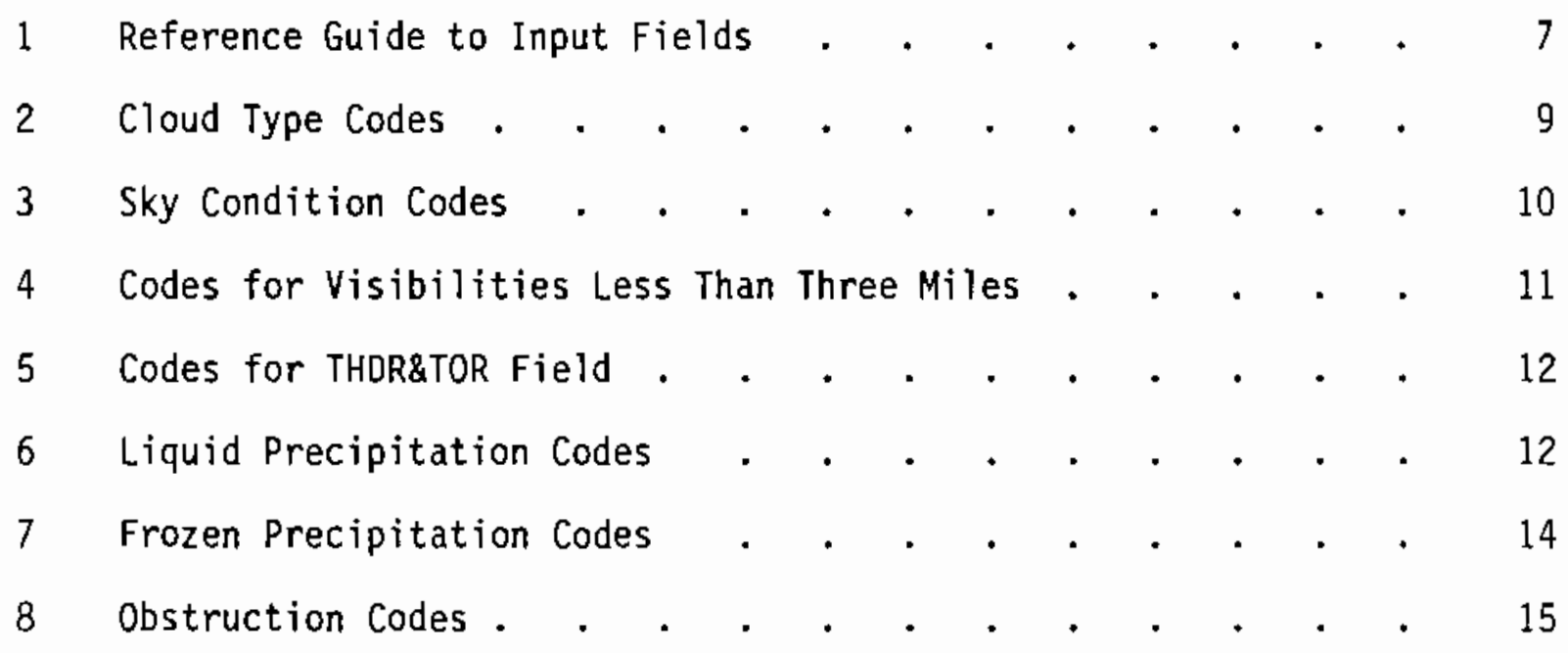

$x$ 


\section{INTRODUCTION}

The Hanford Meteorological Station (HMS) was established in 1944 on the Hanford Site to collect and archive meteorological data and to provide weather forecasts and related services for Hanford project activities. The HMS is located in the northwest quadrant of the Hanford Site and is operated by the Pacific Northwest Laboratory (PNL).

Surface weather observations are recorded and archived each hour throughout the year at the HMS. These observations, hereafter referred to as the hourly surface observations, consist of weather phenomena such as cloud type and coverage; dry bulb, wet bulb, and dew point temperatures; relative humidity; atmospheric pressure; and wind speed and direction. Forecasters use the SFC computer code to archive and apply quality assurance checks to the hourly surface observations. The archive is maintained in disk files on the HMS computer system (DEC VAX 11/750).

The U.S. Department of Commerce (1982) provides a guide to the method used for coding the surface observations. This guide is kept in the forecast room at the HMS.

The following sections in the volume describe the implementation and operation of the SFC computer code. Appendix A contains a description and flowchart of the SFC computer code and Appendix B contains a source listing of the code. 
= 


\section{THE SFC COMPUTER CODE}

The SFC computer code is the primary method for archiving data obtained from hourly surface observations. The code has replaced manual entry of data via computer cards and a keypunch. The SFC code was written, compiled, and linked on the DEC VAX 11/750 at the HMS and is executed once an hour.

\section{PROGRAM OVERVIEW}

The SFC computer code accesses one input file and one output file. The input file contains the previous archive's date and hour, and the output file consists of hourly surface observations for the current day (Refer to Appendix A for more information about input/output operations.)

The program begins by displaying a data entry form on the terninal screen (Figure 1). The length of each field is indicated by the number of $X$ 's adjacent to the field name. The program fills in the date and hour fields by accessing an input file to obtain the previous archive's date and hour. You are then prompted to enter data for the remaining input fields. You can exit the data entry form after filling in all the input fields. The screen clears, and a prompt to make any needed corrections appears on the screen. Once all the input values are correct, you can exit the program and the hourly surface observation is appended to the current daily surface observation file. During the graveyard shift the next day, the daily surface observation file is appended to the current monthly surface observation file. (For example, hourly surface observation data for September 5 is archived to the September monthly surface observation file during the September 6 graveyard shift.) Volume 7 of this series (The RIVER Computer Code) further describes how the daily surface observation file is appended to the monthly surface observation file.

\section{USER'S GUIDE FOR THE SFC COMPUTER CODE}

This section describes how the SFC computer code is invoked on the HMS DEC VAX 11/750 computer and how to respond to the various prompts associated with the code. We assume that you know how to access the FCST account on the HMS computer, and that you have a basic working knowledge of the VAX 
HMS SURFACE OBSERVATION INPUT FORM

CLOUDS: $x x x x x$ DATE: $x x x x x x$ HOUR: $x x$ CEILING HT: $x x x$

SKY COND: $x x x x$ VISIBILITY: $x x x$ THDR\&TOR: $x$ LQ PRECIP: $x x$

FR PRECIP: $x x x$ OBSTRCTNS: $x x$ SEA PRESS: $x x x x$ DEW POINT: $x x x$

WIND DIR: $x x$ WIND SPD: $x x$ STN PRESS: $x \times x x$ DRY BULB: $x x x$

$\begin{array}{llll}\text { WET BULB : } x x x & \text { REL HUM: } x x x \text { SKY COVER: } x x & \text { RAIN }: x x\end{array}$

SNOW EQ: $x x \quad$ SNOW UN: $x x$ WX INDCTR: $x \quad$ SOLRAD: $x x x$

FIGURE 1. Example of the Data Entry Form Used by the SFC Computer Code

operating system. The terminal must be in the DEC VT100 terminal mode to use the data entry form. Currently, the HMS is equipped with several Tektronix 4107 terminals that can emulate the VT100 teminal. To determine the terminal status, simply type SHOW TERMINAL and depress the RETURN key. A list of terminal characteristics appears on the screen. Check to make sure the terminal type is set to VT100. If it is not, type SET TERMINAL/VT100 and depress the RETURN key.

Basically, there are six steps to executing the SFC computer code, filling in the data entry form, and terminating the program. These steps are listed below, and each step is discussed in detail in the following paragraphs:

- $\log$ in to the HMS computer (need the FCST password)

- type RUN SFC, then depress the RETURN key

- fill in the data entry form

- exit the form

- answer "yes" or "no" to "need corrections" prompt

- terminate program.

To $\log$ in, depress the RETURN key a couple of times. The computer responds with the prompt USERNAME:. Enter FCST and depress the RETURN key. The computer then responds with the prompt PASSWORD:. You must know the password to the 
FCST account before logging in to the HMS computer. Enter the correct password. If you fail to answer either of these prompts correctly, the computer repeats the appropriate prompt. You are given three chances to enter the correct response. When you successfully log into the FCST account, you are placed in the [FCST] directory and can imnediately invoke the SFC computer code.

The SFC code is invoked by typing RUN SFC and depressing the RETURN key. When this is done, the screen clears and the data entry form appears on the terminal. You can now begin data entry. If problems occur when executing the code, refer to the "Trouble-Shooting" section for help.

The data entry form appears on the screen as shown in Figure 1 with the cursor in field one (CLOUDS). The date and hour fields (second and third fields, respectively) are filled in by the program. When the cursor is moved to a new field, a prompt for the field appears on the screen below the data entry form. Included with each prompt is a default value and a valid range or list of matching values from which the input must be selected. To enter data into a field, simply type in the requested data and depress the RETURN key. Integers are used for all input. The default value may be entered by depressing the ENTER key or the SELECT DEFAULT key, which is found on some Tektronix terminals. The input value appears in the field (assuming a valid value or default value was entered) while the cursor moves from left to right into the next field. After data are entered in the rightmost field, the cursor moves down one line to the leftmost field. When values have been entered in all the fields, you should check the fields for mistakes. If corrections are needed use the up, down, right, and left arrow keys $(\uparrow, t, t, t)$ located at the top of the keyboard to move within the form. Once you are satisfied the entered values are correct, depress the EXIT key to exit the form. You may exit the data entry form from any field.

The SFC program provides for two phases of quality assurance to the input data. The first phase is applied as you enter the input data for each field. An error message appears at the bottom of the form if the input value is not within the valid range or valid list of matching numbers. If the input value is not in the acceptable range, you are given the opportunity to enter another value for that field. The second phase occurs when you exit the form and the 
"need corrections" prompt appears below the information entered in the form. You can check the input values for validity and make necessary corrections.

After exiting the form, the program displays the information entered into the data entry form on the terminal in the format in which it is appended to the daily file. A prompt appears just below the information asking if you would care to make any corrections. If no corrections are needed, enter an $\mathrm{N}$ or $\mathrm{n}$ and the program appends the data to the daily file. If corrections are needed, enter a $Y$ or $y$ and the program returns to the data entry form mode. This time, the previously entered values appear in their respective fields. Incorrect value(s) can be corrected by using the arrow keys to move the cursor to the appropriate field(s) and revising the incorrect entry. When all corrections have been made, you can exit the form by depressing the EXIT key. You may exit the data entry form from any field; it is not necessary to move to the last field.

The SFC program is terminated by answering $n$ or $N$ to the "need corrections" prompt. The entered data are appended to the daily file and the program terminates with a FORTRAN STOP message written to your terminal. The data file DAILYSFCOBS.DAT is located in the [FCST.DAT] directory. This file contains the hourly surface observations for the current day.

\section{DESCRIPIION OF INPUT}

The data entry form consists of 24 fields. You must provide integer values for 22 of these fields. The program provides the value for the second and third fields, which are the date and hour fields. When you move the cursor to one of the other 22 input fields, the code provides a prompt related to the required input. The prompt consists of a brief description of the field, the valid range or list of matching numbers from which the input value must be selected, and a default value (refer to the "User's Guide" section for information on how to input the default value). Table 1 describes each of the input fields. 
TABLE 1. Reference Guide to Input Fields

\begin{tabular}{|c|c|c|}
\hline Input Field & Description & Range or List \\
\hline CLOUDS & code & $0-99900 / 0$ \\
\hline DATE & YYMMDD & $860101-990101 / 999999$ \\
\hline HOUR & hour of day & $1-24 / 99$ \\
\hline CELING HT & height of cloud base ${ }^{(a)}$ & $0-300 / 0$ \\
\hline SKY COND & code & $0-9800 \& 9998-9999 / 0$ \\
\hline VISIBILITY & miles and fraction of miles & $0-150 / 150$ \\
\hline THDR\&TOR & code & $0-5 \quad / 0$ \\
\hline LQ PRECIP & code & $4-99 / 0$ \\
\hline FR PRECIP & code & $1-999 / 0$ \\
\hline OBSTRCTNS & code & $1-55 / 0$ \\
\hline SEA PRESS & millibars & $9700-9999 \& 0-538$ / 9999 \\
\hline DEW POINT & ${ }^{\circ} \mathrm{F}$ & $-30-90 / 999$ \\
\hline WIND DIR & tens of degrees & $0-37 / 99$ \\
\hline WIND SPD & miles per hour & $0-55 / 99$ \\
\hline STN PRESS & inches of mercury & $2810-3023 / 9999$ \\
\hline DRY BULB & ${ }^{\circ} \mathrm{F}$ & $-37-125 / 999$ \\
\hline WET BULB & ${ }^{\circ} \mathrm{F}$ & $-37-125 / 999$ \\
\hline REL HUM & percent & $1-100 / 999$ \\
\hline SKY COVER & tenths & $0-10 / 0$ \\
\hline RAIN & hundredths of inches & $0-37 \& 49-50 / 0$ \\
\hline SNOW EQ & hundredths of inches & $0-50 \& 49-50 / 0$ \\
\hline SNOW UN & tenths of inches & $0-30 \& 49-50 / 0$ \\
\hline WX INDCTR & code & 0 or $9 / 0$ \\
\hline SOLRAD & hundredths of langleys/min & $0-200 \& 500 / 0$ \\
\hline
\end{tabular}


The following list describes each input field, the associated range or list of matching values from which the input must be selected, and the default. value. Surface observations are normally recorded 10 minutes before the hour.

1) CLOUDS - The input value for this field is the type of cloud at the time of observation. Cloud type observations are recorded every 3 hours. Up to five cloud types can be entered, although it is unusual to enter more than three types. Cloud types are ordered by height. The lowest cloud type is recorded in the first column, the next layer is recorded in the second column, etc. The value entered is a code, as indicated in Table 2. The range of possible codes is from 00000 through 99900, with a default value of 00000 . The default value indicates no clouds were observed.

2) DATE OF FORECAST - The date format is YYMMDD: where YY is the last two digits of the current year (e.g., 87 for 1987), MM is the numerical equivalent of the month (e.g., 04 represents April), and $D D$ is the day of the month. An example of a date is 870421 , which is April 21, 1987. The range of the date is 860101 (i.e., January 1,1986 ) through 990101 (i.e., January 1, 1999). The default value for the date (refer to the User's Guide Section for details on entering default values) is 999999 . This value indicates that the date is missing for the hourly surface observation.

3) HOUR - The input value for this field is the hour (always Pacific Standard Time) of the day. The range is 1 through 24 , with a default of 99 . The value 15 represents the hour 1500 on a 24 -hour clock, or 3:00 p.m. using the normal convention. The default value indicates the hour was missing for that observation.

4) CELING HT - The input value for this field is the height of the lowest cloud base that is either broken (.6 through .9 of sky covered) or overcast. The value 250 indicates a cloud height of $25,000 \mathrm{ft}$ (values are recorded in hundreds of feet). The range is 000 through 300 , with a default value of 000 . The default value indicates no cloud ceiling. 
TABLE 2. Cloud Type Codes

$\begin{array}{cl}\frac{\text { Code }}{1} & \text { Cloud Type } \\ 2 & \text { Fog } \\ 3 & \text { Status } \\ 4 & \text { Stratocumulus } \\ 5 & \text { CumuTus } \\ 6 & \text { Cumulonimbus } \\ 7 & \text { Altostratus } \\ 8 & \text { Altocumulus } \\ 9 & \text { Cirrus }\end{array}$

5) SKY COND - The input value for this field is a code or codes for each layer of cloud in the sky. Sky conditions are categorized into six general conditions and up to four conditions can be entered:

- clear

- scattered (.1 through .5 sky covered)

- broken (.6 through .9 sky covered)

- overcast

- total obscuration

- partial obscuration (.1 through .9 sky covered)

See U.S. Department of Commerce (1982) for details on coding sky conditions. The input value is a code that describes the sky condition of each cloud layer in the sky at the time of observation. The first digit in the entry indicates the sky condition of the lowest cloud layer, the second digit indicates the sky condition for the next highest cloud layer plus the lower layer, and so on. An input value of 2580 describes the following sky condition: 2 indicates scattered sky conditions for the lowest cloud layer, 5 indicates broken sky conditions for the next highest cloud layer plus the lower layer, 8 indicates overcast sky conditions for the next highest cloud layer plus the two lower layers, and 0 indicates there is no fourth cloud layer or the sky is fully covered by the 
lower layers. Clear skies are coded as 0000. Table 3 describes each sky condition code. The code 9 is used to describe two types of sky conditions. See U.S. Department of Commerce (1956) for a more thorough description of code 9 and other sky condition codes. (A copy of this manual is in the weather forecasting room at the HMS.) The two ranges for this field are 0000 through 9800 and 9998 through 9999 . The default value is 0000 , which indicates clear sky conditions.

\section{TABLE 3. Sky Condition Codes}

\begin{tabular}{|c|c|c|}
\hline$\underline{\text { Code }}$ & Description & Example \\
\hline 1 & Thin scattered & $\begin{array}{l}\text { Patches of thin cirrus; } \\
\text { no ceiling }\end{array}$ \\
\hline 2 & Scattered & $\begin{array}{l}\text { A few cumulus clouds; } \\
\text { no ceiling }\end{array}$ \\
\hline 3 & Heavy scattered & $\begin{array}{l}\text { Dark cumulus clouds; } \\
\text { no ceiling }\end{array}$ \\
\hline 4 & Thin broken & $\begin{array}{l}\text { Large patches of } \\
\text { cirrus; no ceiling }\end{array}$ \\
\hline 5 & Broken & $\begin{array}{l}\text { Large patches of } \\
\text { altostratus; ceiling }\end{array}$ \\
\hline 6 & Heavy broken & $\begin{array}{l}\text { Thick large patches of } \\
\text { altostratus; ceiling }\end{array}$ \\
\hline 7 & Thin overcast & $\begin{array}{l}\text { Cirrostratus covering } \\
\text { entire sky; no ceiling }\end{array}$ \\
\hline 8 & Overcast & $\begin{array}{l}\text { Altostratus covering } \\
\text { entire sky; ceiling }\end{array}$ \\
\hline 9 & Heavy overcast & $\begin{array}{l}\text { Nimbostratus covering } \\
\text { sky; ceiling }\end{array}$ \\
\hline 9000 & Partial obscuration & Ground fog \\
\hline 9999 & Total obscuration & Fog enclosing station \\
\hline
\end{tabular}


6) VISIBILTY - The input value for this field is the horizontal visibility in miles when the visibility is equal to or greater than 3 miles. For example, 050 indicates a horizontal visibility of 5.0 miles. The visibility is never greater than 15 miles because of surrounding mountain ranges. Visibility of less than 3 miles is recorded in miles and fractions of miles. Table 4 lists the codes for visibilities less than 3 miles. For example, the code 005 indicates a horizontal visibility of $5 / 16$ of a mile. The code 001 indicates a visibility of $1 / 16$ of a mile. The range is 0 through 150 with a default value of 150 . The default value indicates a horizontal visibility of 15.0 miles.

IABLE 4. Codes for Visibilities Less Than Three Miles

$\begin{array}{lc}\frac{\text { Code }}{001} & \text { Visibility (mi) } \\ 002 & 1 / 16 \\ 003 & 1 / 8 \\ 004 & 3 / 16 \\ 005 & 1 / 4 \\ 006 & 5 / 16 \\ 007 & 3 / 8 \\ 008 & 1 / 2 \\ 009 & 5 / 8 \\ 009\end{array}$

7) THDR\&TOR - The input value for this field is a code that indicates whether thunder was heard or a tornado was sighted. Table 5 describes the codes. The codes range from 0 through 5 . The default value is 0 , which indicates no thunder was heard or no tornado was sighted at the time of observation.

8) LQ PRECIP - The input value for this field is a code that indicates the type of liquid precipitation at the time of observation. Table 6 describes each code. 
TABLE 5. Codes for THDR\&TOR Field

$\begin{array}{ll}\frac{\text { Code }}{1} & \frac{\text { Description }}{\text { Distance thunder }} \\ 2 & \text { Loud thunder (overhead) } \\ 3 & \text { Tornado sighted } \\ 4 & \text { Not used } \\ 5 & \text { Squall }\end{array}$

TABLE 6. Liquid Precipitation Codes

$\begin{array}{ll}\text { Code } & \text { Type of Precipitation } \\ 01 & \text { Not used } \\ 02 & \text { Not used } \\ 03 & \text { Not used } \\ 04 & \text { Light drizzle } \\ 05 & \text { Moderate drizzle } \\ 06 & \text { Heavy drizzle } \\ 07 & \text { Light freezing drizzle } \\ 08 & \text { Moderate freezing drizzle } \\ 09 & \text { Heavy freezing drizzle } \\ 10 & \text { Light rain } \\ 20 & \text { Moderate rain } \\ 30 & \text { Heavy rain } \\ 40 & \text { Light rain shower } \\ 50 & \text { Moderate rain shower } \\ 60 & \text { Heavy rain shower } \\ 70 & \text { Light freezing rain } \\ 80 & \text { Moderate freezing rain } \\ 90 & \text { Heavy freezing rain }\end{array}$


Two kinds of precipitation may be recorded at the time of observation, such as light rain and heavy drizzle. These types are indicated by an input value of 16 . The range of possible codes is 04 through 99 , with a default value of 00 . The default value indicates no liquid precipitation at the time of observation. The U.S. Department of Commerce (1982) provides the definitions of light, moderate, and heavy liquid precipitation.

9) FR PRECIP - The input value for this field is a code that indicates the type of frozen precipitation at the time of observation. Table 7 describes each code. Two types of precipitation may be recorded at the time of observation, such as light snow and light snow grains. These types are indicated by an input value of 170 . The range of possible codes is 001 through 999, with a default value of 000 . The default value indicates no frozen precipitation at the time of observation. The U.S. Department of Commerce (1982) provides the definitions of light, moderate, and heavy frozen precipitation.

10) OBSTRCTNS - The input value for this field is a code that indicates the type of obstruction to vision (e.g., smoke, haze, dust) at the time of observation. Table 8 describes each code. Two types of obstructions may be recorded at the time of observation, such as fog and blowing snow. These obstructions are indicated by an input value of 15. The range of possible codes is 01 through 55, with a default value of 0 . The default value indicates no obstruction at the time of observation.

11) SEA PRESS - The input value for this field is the sea level pressure in tenths of millibars (mb) at the time of observation. When the sea level pressure is greater than or equal to $1000 \mathrm{mb}$ the 10 is assumed. For example, a sea level pressure of $1023.6 \mathrm{mb}$ is recorded as 236. When the pressure is below $1000 \mathrm{mb}$ the entire pressure is recorded; for example, $993.6 \mathrm{mb}$ is recorded as 9936 . The range is 9700 through 9999 and 0000 through 538, with a default value of 7777. The default value indicates a rising sea level pressure. 
IABLE 7. Frozen Precipitation Codes

\begin{tabular}{|c|c|}
\hline Code & Type of Precipitation \\
\hline 001 & Light sleet \\
\hline 002 & Moderate sleet \\
\hline 003 & Heavy sleet \\
\hline 004 & Not used \\
\hline 005 & Moderate hail \\
\hline 006 & Not used \\
\hline 007 & Not used \\
\hline 008 & Not used \\
\hline 009 & Not used \\
\hline 010 & Light snow showers \\
\hline 020 & Moderate snow showers \\
\hline 030 & Heavy snow showers \\
\hline 040 & Not used \\
\hline 050 & Not used \\
\hline 060 & Not used \\
\hline 070 & Light snow grains \\
\hline 080 & Moderate snow grains \\
\hline 090 & Heavy snow grains \\
\hline 100 & Light snow \\
\hline 200 & Moderate snow \\
\hline 300 & Heavy snow \\
\hline 400 & Light snow pellets \\
\hline 500 & Moderate snow pellets \\
\hline 600 & Heavy snow pellets \\
\hline 700 & Light ice crystals \\
\hline 800 & Moderate ice crystals \\
\hline 900 & Heavy ice crystals \\
\hline
\end{tabular}


TABLE 8. Obstruction Codes

$\begin{array}{cl}\frac{\text { Code }}{01} & \text { Description } \\ 02 & \text { Smoke } \\ 03 & \text { Haze } \\ 04 & \text { Smoke/Haze } \\ 05 & \text { Dust } \\ 10 & \text { Blowing Snow } \\ 20 & \text { Fog } \\ 30 & \text { Ice Fog } \\ 40 & \text { Ground Fog } \\ 50 & \text { Blowing Dust }\end{array}$

12) DEW POINT - The input value for this field is the dew point temperature in whole ${ }^{\circ} \mathrm{F}$ at the time of observation. The temperature $36^{\circ} \mathrm{F}$ is recorded as 036 . Negative values are represented with a minus sign. The temperature $-10^{\circ} \mathrm{F}$ is recorded as -10 . The range of possible values is -30 through 090, with a default value of 999 . The default value indicates a missing dew point temperature.

13) WIND DIR - The input value for this field is a 5-minute average of the wind direction in tens of degrees at the time of observation. For example, a north wind direction would be recorded as 36 . Calm conditions are recorded as 00 . Variable wind directions are recorded as 37 . The range of possible values is 0 through 37 , with a default value of 99 . The default value represents a missing wind direction.

14) WIND SPD - The input value for this field is a 5-minute average of the wind speed in whole miles per hour ( $\mathrm{mi} / \mathrm{hr}$ ) at the time of observation. Calm conditions are recorded as 00 . The range of possible values is 0 through 55 , with a default value of 99 . The default value indicates a missing wind speed.

15) STN PRESS - The input value for this field is the station pressure in hundredths of inches-of-mercury $(\mathrm{in.} / \mathrm{Hg})$ at the time of 
observation. A station pressure of 30.00 is recorded as 3000 . The range of possible values is 2810 through 3023 , with a default value of 9999 . The default value indicates a missing station pressure.

16) DRY BULB - The input value for this field is the dry bulb temperature . in whole ${ }^{\circ} \mathrm{F}$ at the time of observation. A dry bulb temperature of $75^{\circ} \mathrm{F}$ is recorded as 75 , while a temperature of $110^{\circ} \mathrm{F}$ is recorded as 110. Negative dry bulb temperatures are recorded with a minus sign. A temperature of $-13^{\circ} \mathrm{F}$ is recorded as -13 . The range of possible values is -37 through 125 , with a default value of 999 . The default value indicates a missing dry bulb temperature.

17) WET BULB - The input value for this field is the wet bulb temperature in whole ${ }^{\circ} \mathrm{F}$ at the time of observation. A wet bulb temperature of $75^{\circ} \mathrm{F}$ is recorded as 75 , while a temperature of $110^{\circ} \mathrm{F}$ is recorded as 110. Negative wet bulb temperatures are recorded with a minus sign. A temperature of $-13^{\circ} \mathrm{F}$ is recorded as -13 . The range of possible values is -37 through 125 , with a default value of 999 . The default value indicates a missing wet bulb temperature.

18) REL HUM - The input value for this field is the relative humidity in whole percent at the time of observation. The range of possible values is 1 through 100, with a default value of 999 . The default value indicates a missing relative humidity.

19) SKY COVER - The input value for this field is the sky cover in tenths at the time of observation. For example, a value of 05 indicates that one half of the sky is covered. The range of possible values is 0 through 10, with a default value of 0 . The default value indicates clear sky conditions.

20) RAIN - The input value for this field is the amount of liquid precipitation in hundredths of an inch recorded during the hour. A value of 04 indicates that four-hundredths of an inch of rain fell during the hour. A trace of liquid precipitation is recorded as 50. The range of possible values is 00 through 37 and 49 through 50, with a default value of 00 . The default value indicates no liquid precipitation was recorded during the hour. 
21) SNOW EQ - The input value for this field is the amount of frozen precipitation in water equivalent form that accumulated during the hour. The units are in hundredths of an inch. An input value of 04 indicates that four-hundredths of an inch (water equivalent) of snow fell during the hour. A trace of frozen precipitation is recorded as 50. The range of possible values is 00 through 50 and 49 through 50, with a default value of 00 . The default value indicates no frozen precipitation was recorded during the hour.

22) SNOW UN - The input value for this field is the amount of unmelted snow in tenths of inches that fell during the hour. An input value of 04 indicates that .4 inch of snow fell during the hour. A trace of snow is recorded as 50 . The range of possible values is 0 through 30 and 49 through 50 , with a default value of 0 . The default value indicates no snow fell during the hour.

23) WX INDCTR - The input value for this field is a code indicating if a weather event (all precipitation and obstruction events) ended during the hour. The code is 9 . The list of matching values is 0 or 9 , with a default value of 0 . The default value indicates a weather event did not end during the hour.

24) SOLRAD - The input value for this field is a 1-hour average of the solar radiation in hundredths of langley-per-minute $(1 \mathrm{y} / \mathrm{min})$. An hourly average of $1.0 \mathrm{ly} / \mathrm{min}$ is recorded as 100 . A trace of solar radiation is recorded as 500 . The range is 000 through 200 , with a default value of 000 . 
-

• 


\section{TROUBLE-SHOOTING THE SFC COMPUTER CODE}

This section provides information that may help resolve problems that occur when operating the SFC computer code. We assume that you are familiar with the VAX EDT editor and the VAX operating system commands. Basically, there are three types of failure or problem areas: terminal (i.e., CRT), system, and/or program. The following sections will discuss problems or failures that may occur when using the SFC computer code and the suggested recovery procedures. If a series of recovery actions are suggested, you should try them in sequence until the problems or failure are resolved. Remember the date and hour are incremented each time you execute the SFC program. Therefore, you may need to edit the [FCST.PREVIOUS_DATE]SFCOBS_DATE.DAT file to reflect the desired date and hour after you have tried the recovery procedures.

\section{TERMINAL PROBLEMS/FAILURES}

Problem: Terminal does not respond.

Recovery: Determine if terminal is on. On Tektronix terminals the on/off switch is located in the front and to the right.

Determine if the dimner switch is turned all the way down. On Tektronix teminals the dimmer switch is located in the front and to the right. Turn the switch clockwise to increase the light intensity on the screen.

If the above actions fail to get a response from the terminal, ask the instrument specialist (the HMS Room 125) to check the terminal.

\section{SYSTEM PROBLEMS/FAILURES}

Problem: System does not respond to operating system commands or carriage returns.

Recovery: Check with the Emergency Meteorological System (EMS) computer manager (Eric Stephan, 376-1107, or Ora Gifford, 373-3216) to see if the HMS computer system is down for maintenance or repair. 
If the EMS computer manager indicates the HMS computer system is operating, turn the terminal off, wait approximately 15 to 20 seconds, and turn the terminal back on. Depress the RETURN key several times to get the attention of the computer system. If the above actions fail ask an instrument specialist to examine the computer and notify the EMS computer manager.

\section{PROGRAM PROBLEMS/FAILURES}

Problem: Terminal not correctly displaying data entry form.

Recovery: Depress the CTRL key and the $Y$ key simultaneously to get to the dollar sign prompt. Type SET TERMINAL/VT100 and depress RETURN. Try running the program again.

Depress the SETUP key at the top of the keyboard. The terminal should respond with an asterisk. Type CODE ANSI and depress RETURN, then depress the SETUP key. Try running the program again.

Problem: Terminal displaying garbled data.

Recovery: Depress the SETUP key at the top of the keyboard. The terminal should respond with an asterisk. Type CODE ANSI, depress RETURN, then depress the SETUP key.

Problem: Program SFC.EXE cannot be found or program has been "trashed" in some way.

Recovery: Copy backup version to the FCST directory. Type COPY [FCST.DATA_ENTRY]SFC.EXE [FCST]SFC.EXE. Try program again.

Problem: Input file ([FCST.PREVIOUS_DATE]SFCOBS_DATE.DAT) or output file ([FCST.DAT]DAILYSFCOBS.DAT) cannot be found.

Recovery: Check the [FCST.PREVIOUS_DAT] directory for the input file or the [FCST.DAT] directory for the output file. If the file(s) is intact, try copying the backup version of SFC.EXE to the [FCST] directory (see above for directions). Try running the code again. 


\section{REFERENCES}

U.S. Department of Commerce. 1956. Manual of Card Punching. 6th ed. U.S. Department of Commerce, National Technical Information Service, Springfield, Virginia.

U.S. Department of Commerce. 1982. Federal Meteorological Handbook No. 1 Surface Observations. U.S. Department of Commerce, U.S. Department of Defense, and U.S. Department of Transportation, National Technical Information Service, Springfield, Virginia. 


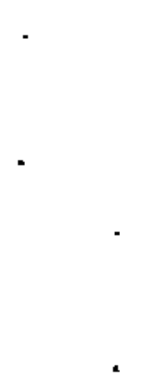


APPENDIX A

PROGRAM DESCRIPTION AND FLOWCHART 
APPENDIX A

\section{PROGRAM DESCRIPTION AND FLOWCHART}

This discussion describes, in detail, the operations and logical flow of the SFC computer code. A flowchart indicating the general operations and logical sequence of the SFC code is shown at the end of this appendix. The flowchart is divided into three sections by two dashed lines. The top and bottom sections are transparent and do not require your input. The middle section involves the data entry form that requires your input. The following three paragraphs describe the operations within each section. For a more indepth review of the operations and logical sequence of the program, refer to the source listing in Appendix B.

The program begins by opening and reading the data in the file SFCOBS_DATE.DAT, which contains one record with the date and hour of the previous archive. The program then reads the data. The SFCOBS_DATE.DAT file resides in the [FCST.PREVIOUS_DATE] sub-directory. Next the program opens the output file DAILYSFCOBS.DAT, which contains the hourly surface observation data for the current day. The DAILYSFCOBS.DAT file resides in the [FCST.DAT] sub-directory. The date and hour are then incremented and entered back into the SFCOBS_DATE.DAT file. At this point the code calls several subroutines that control and display a data entry form at your terminal.

The SFC code uses a data entry form to facilitate data entry. The form consists of several input fields (see Fig. 1 in the main text), each of which represents a surface observation variable. Each field is displayed in reverse video to highlight the field length. The fields are initially blank. You are prompted from the bottom of the form for an input value. The prompt consists of a brief description of the field, the valid range or list of numbers from which input must be selected, and a default value. A valid entry must be made before the cursor moves to the next field. If the numeric value is valid, the number is displayed in the appropriate field and the cursor moves to the next field when the ENTER key is depressed. If the input value is not valid, an error message occurs at the bottom of the form while the cursor remains in that field. When this occurs, the prompt reappears.

\section{A.1}


After entering all the input data, you can terminate the data entry process by depressing the EXIT key on the Tektronix 4107 terminal. The screen then clears and the input data are displayed at the teminal in the data format it will be appended to in the DAILYSFCOBS.DAT file. You are then asked if any corrections are needed before the record is appended to the current daily file. If no corrections are needed, enter an $N$ or $n$ and the surface observation data are appended to the DAILYSFCOBS.DAT file, and a message is displayed on the screen indicating the hourly surface observation data has been appended to the current daily file. The program terminates when the message FORTRAN STOP appears on the terminal. If corrections are needed, enter a $Y$ or $y$ and the code returns to the data entry form with the input values you displayed. You can move to the appropriate input field(s) (refer to the "User's Guide" section for information on how to move the cursor within the form) and change the value(s). Once all the value(s) are corrected, the data record is again displayed on the screen and you are given an opportunity to correct any mistakes.

The DAILYSFCOBS.DAT files are used to archive the hourly surface observation data for the current day. At the end of each day (graveyard shift the next day), the RIVER program (see Vol. 7) is run to append hourly river data to the current day's hourly surface observation data contained in DAILYSFCOBS.DAT. The RIVER program writes the appended data to the end of the monthly surface observations file (e.g., SFCOBSxxx.DAT). See Volume 7 of this series for further details. 


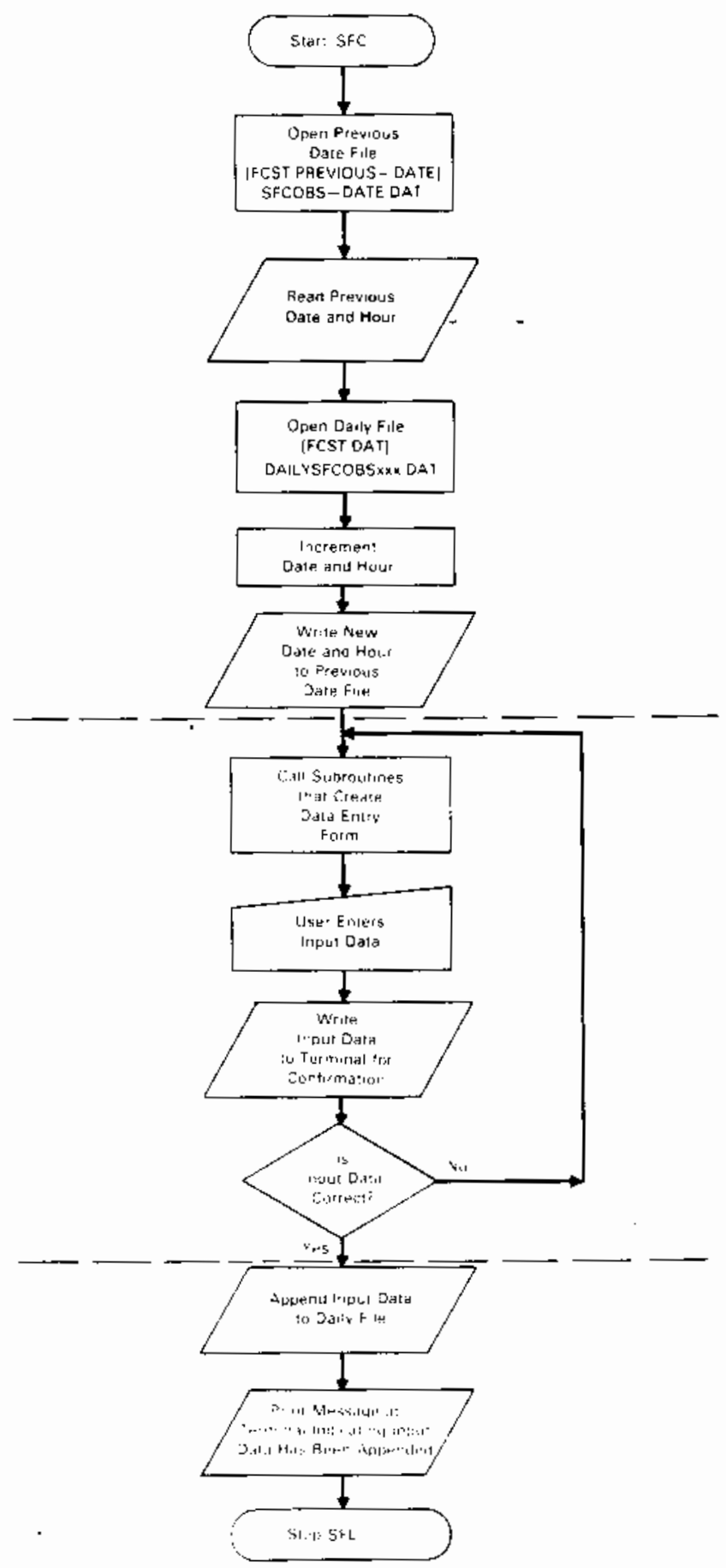

A. 3 


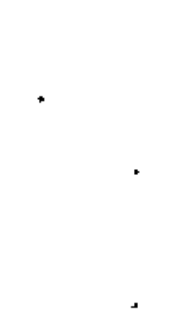


APPENDIX B

SFC SOURCE CODE LISTING 


\begin{tabular}{|c|c|c|}
\hline 9694 & $c$ & PROGRAN: SFCOBS.FQR \\
\hline 0005 & $c$ & \\
\hline 6006 & $c$ & PRGGRAMER: GREGO ANDRENS \\
\hline 6967 & $C$ & \\
\hline 8008 & C & FUNCTION: THIS PROGRAN WS DEYEDPED TO FACILITATE THE \\
\hline 0009 & $c$ & MRCHIVING OF THE HUS SURFACE DBSERVATION DATA. \\
\hline 0810 & $c$ & THE PROGRAL ACCESSES A SCRATCH FILE \\
\hline 0011 & 6 & (SFCOBS_DATE.DAT) TD DETERUYME DATE AKD HOUR OF \\
\hline 0012 & $c$ & LAST DATA ENTRY. PROGRAN THAN INCREMENTS THE DATE \\
\hline 0013 & $c$ & AND HOUR TKRDUCH SOFTWARE. NFTER TKE DATE AND HOUR \\
\hline 0814 & 6 & OF TRE NEXT ENTRY IS DETERNINED IT WKKES CNLLS TO \\
\hline 6015 & 6 & SUBROUTINES THAT CDNTROL THE INPUT FORN. AT THIS \\
\hline 6916 & $c$ & POINT THE FORECASTER ENTERS TKE DATA. GROSS ERROR \\
\hline 0017 & $c$ & CHECXS ARE HADE AND DEALUT YALUES ARE AVAILAQLE \\
\hline 6918 & $c$ & IF NEEDED. ONCE THE DATA IS ENTERED THE FORECASTER \\
\hline 6919 & $c$ & HITS THE EXIT KEY DN THE TEX 4167. THE DATA WIL \\
\hline 6020 & $c$ & APPEAR AS IT IIU BE IRITTEN TO THE QUTPUT FILE \\
\hline 0921 & $c$ & (MDNTHLY) AND ASKS IF TKE DATA IS CDRRECT; \\
\hline 6022 & $c$ & IF NDT THE PROGRAL GOES EACX TO THE FORU MOOE AND THE \\
\hline 6023 & 6 & FDRECASTER IS GIYEN TKE OPPORTUNITY TO WAKE THE \\
\hline 6024 & $c$ & DESIRED CORRECTIONS. \\
\hline
\end{tabular}

CREATED: $1.012 / 85$ a ANDREIS

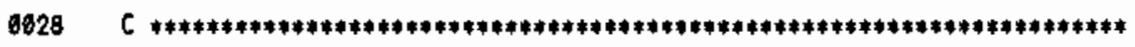

8ะ29

8038

0631

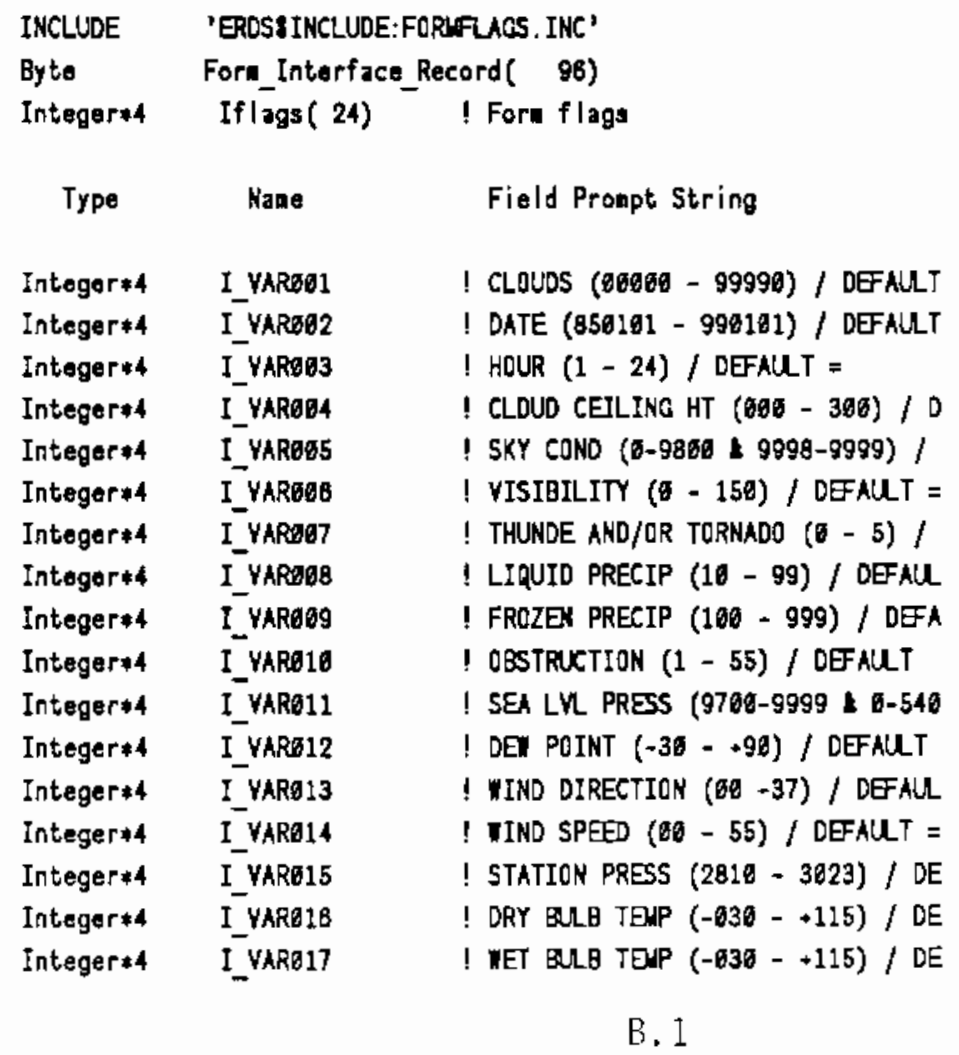




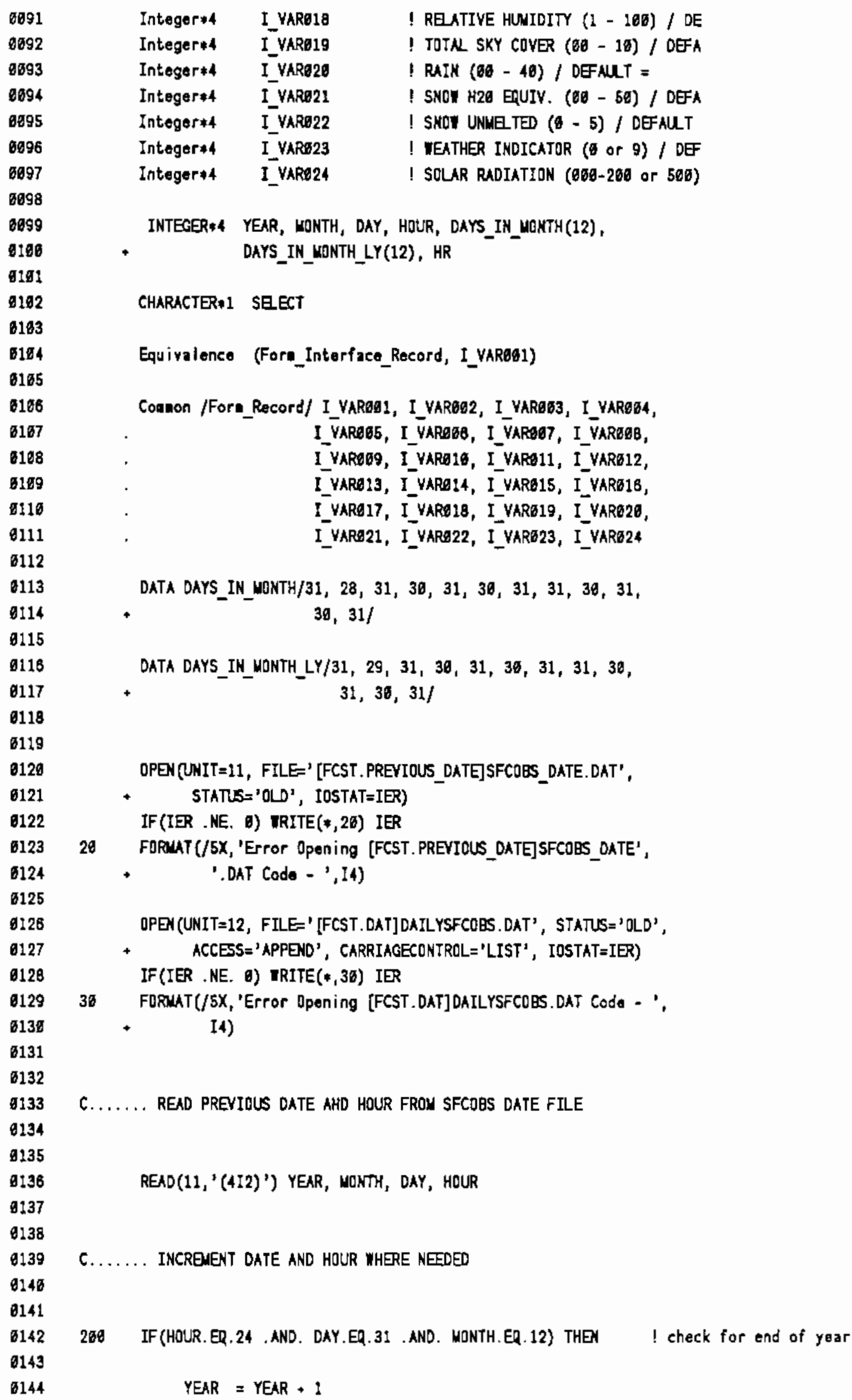

! REATIVE HUNIDITY (1 - 160) / DE

! TOTA SKY COVER (DO - 18) / DEA

! RAIK $(60$ - 40) / DEFALT =

I SNOY H2Q ERUIV. (EO - 5E) / DEA

! SNOW UNWELTED (8 - 5) / DEAUT

! MEATHER INDICATOR (8 or 9) / DE

! SOLAR RADIATION (660-200 Or 506)

INTEGER*4 YEAR, WONTH, DAY, HDUR, DAYS_IN_MOKTH(12), DAYS_IN_WONTH_LY(12), HR

CHARACTER:1 SEECT

Equivalence (Forn_Interface_Record, I_VAR681)

Coanon /Fore_Record/ I VARQ91, I VAR692, I_YARGE3, I YARGO4, I VARE65, I VARE68, I VARQ97, I VAR09B, I_VAR969, I_YARO10, I_VARO11, I_VAR612, I_YARE13, I_YARE14, I_VARB15, I VARG16, I_VAR917, I_VARE18, I_VARB19, I VARO20, I_VARO21, I_VARO22, I_VARG23, I_VARB24

DATA DAYS_IN_MONTH/31, 28, 31, 30,31, 30,31, 31, 30, 31, $39,31 /$

OATA DAYS_IN_MONTH_LY/31, 29, 31, 30, 31, 38, 31, 31, 30, $31,30,31 /$ 


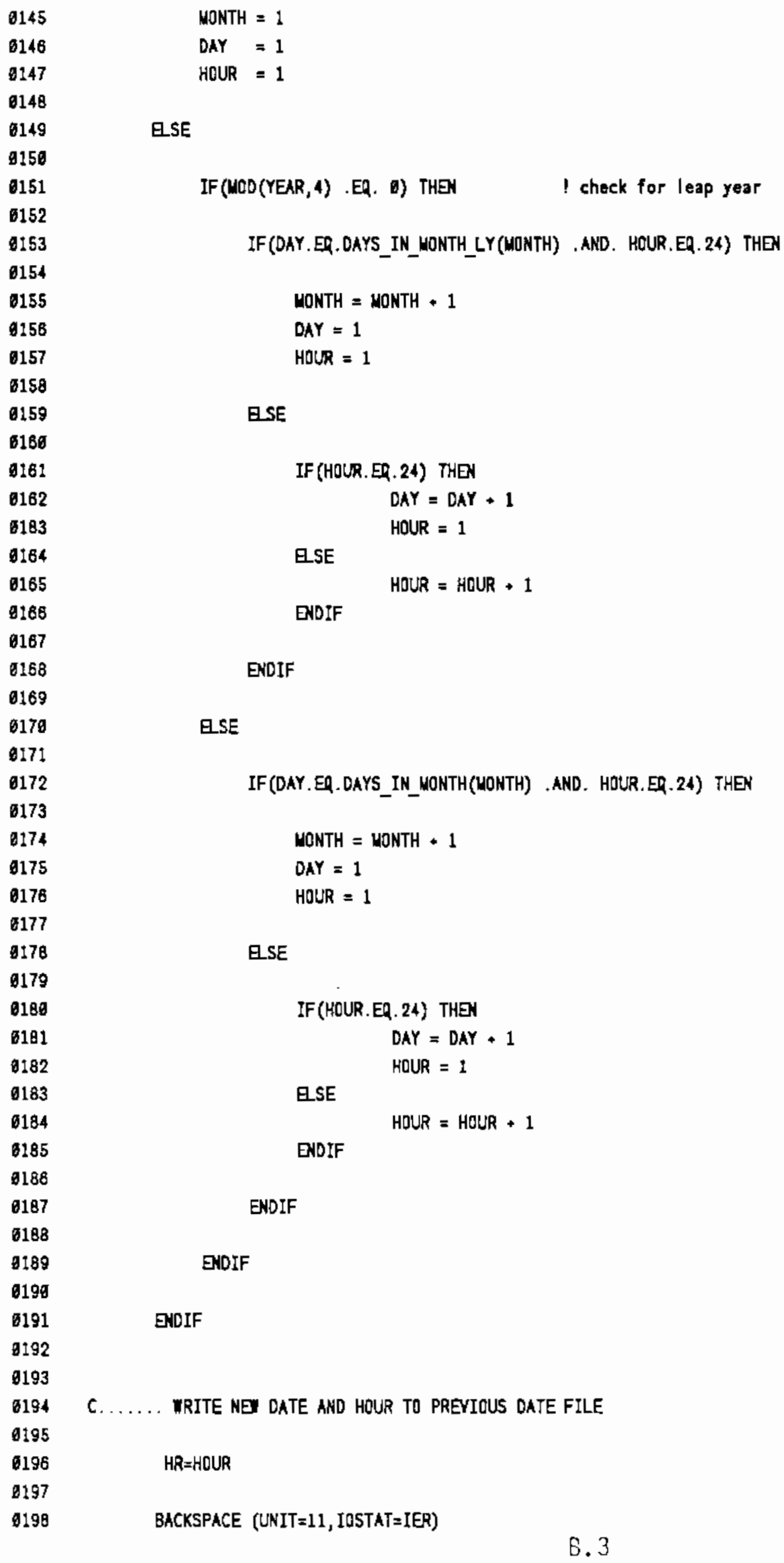

0198

c. 


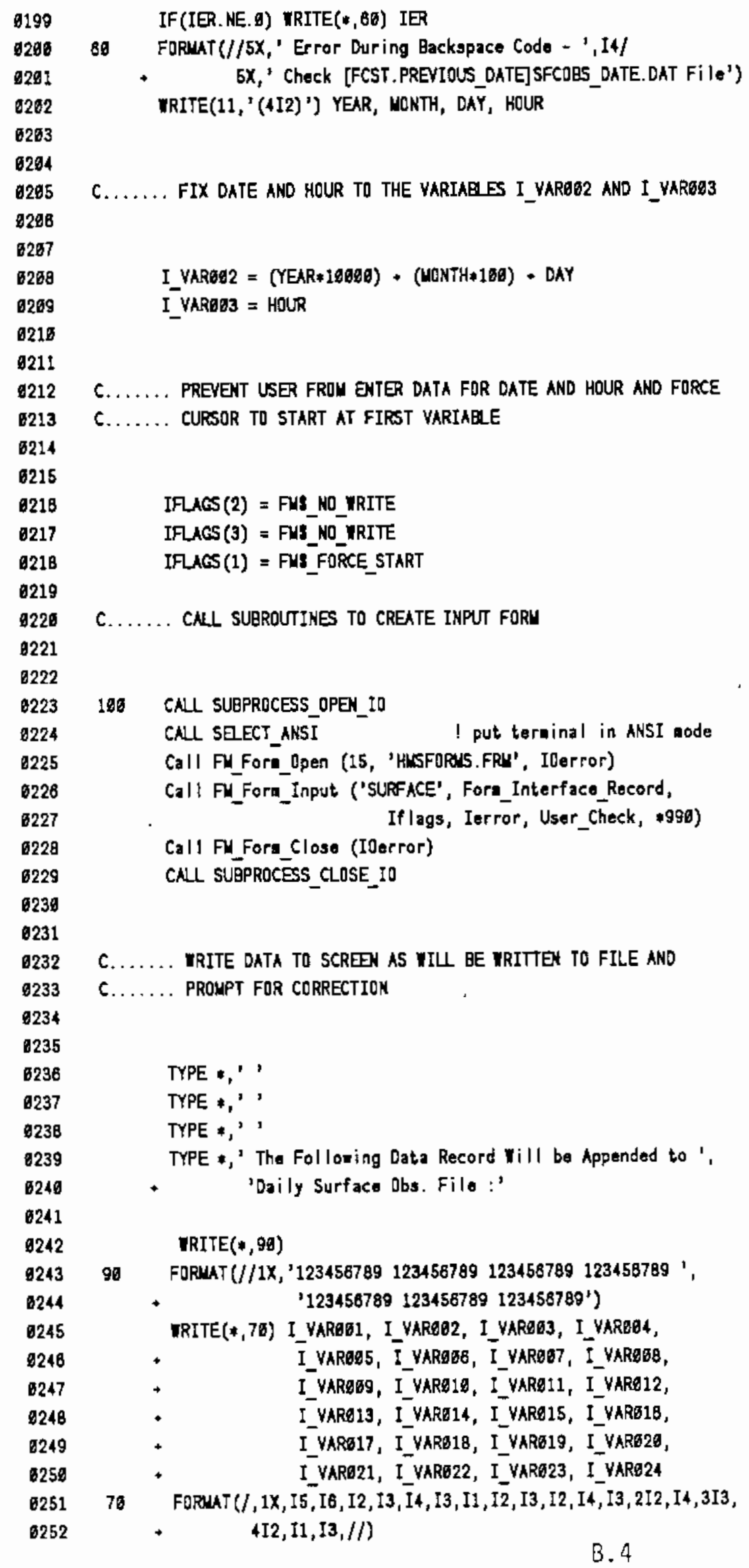




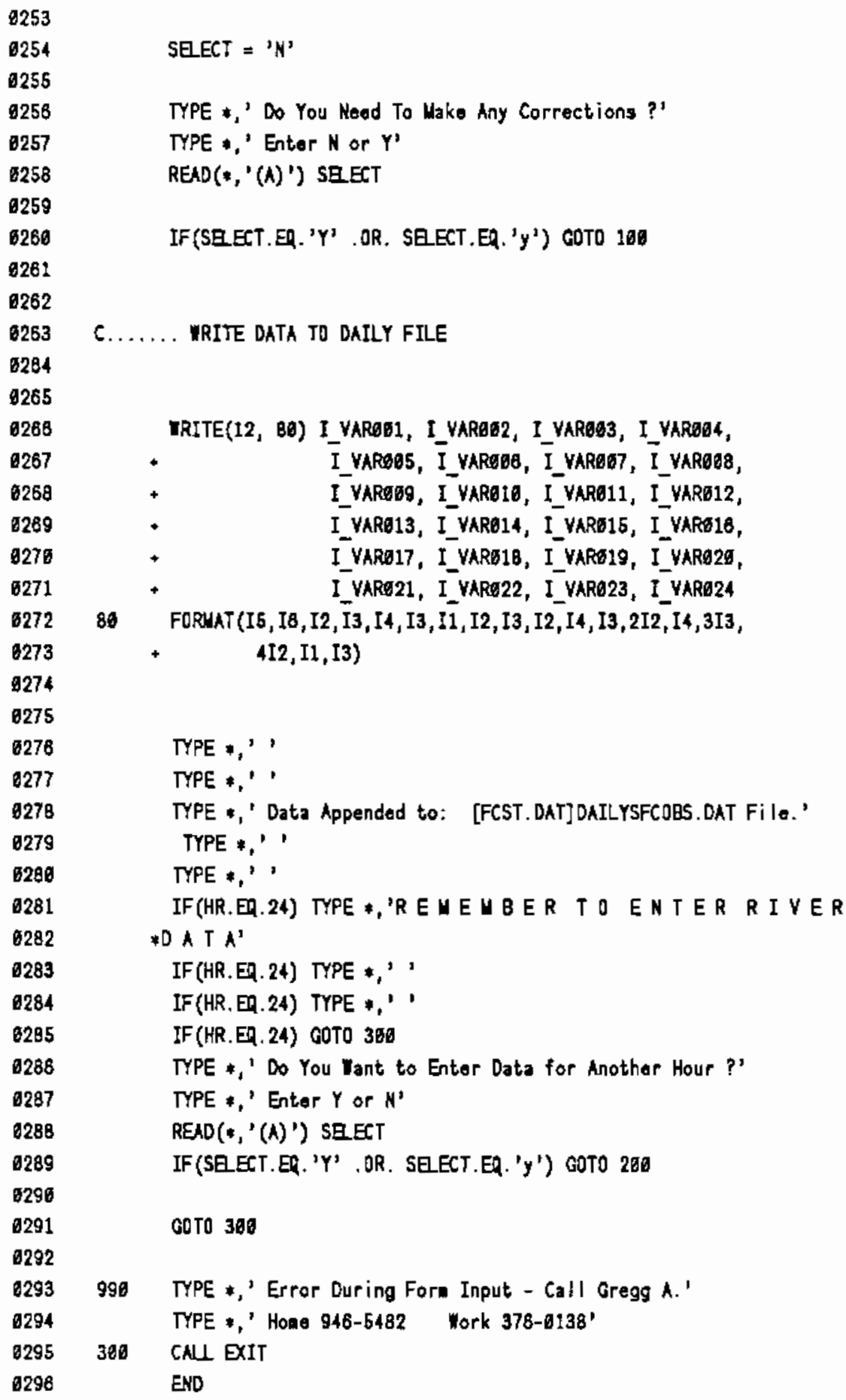

PROGRAM SECTIONS

Name Bytes Attributes

SCDOE
1 SPOATA
2 SLOCN
3 FORN_RECORD

1727 PIC CON REL LCL SHR EXE 832 PIC CON RE LCL SHR NOEXE 476 PIC CON RE LCL NDSHR NOEXE

96 PIC OYR RE GE SHR NDEXE 
ENTRY POINTS
Address Typo Nano
References

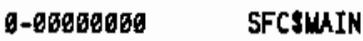

VARIAELES

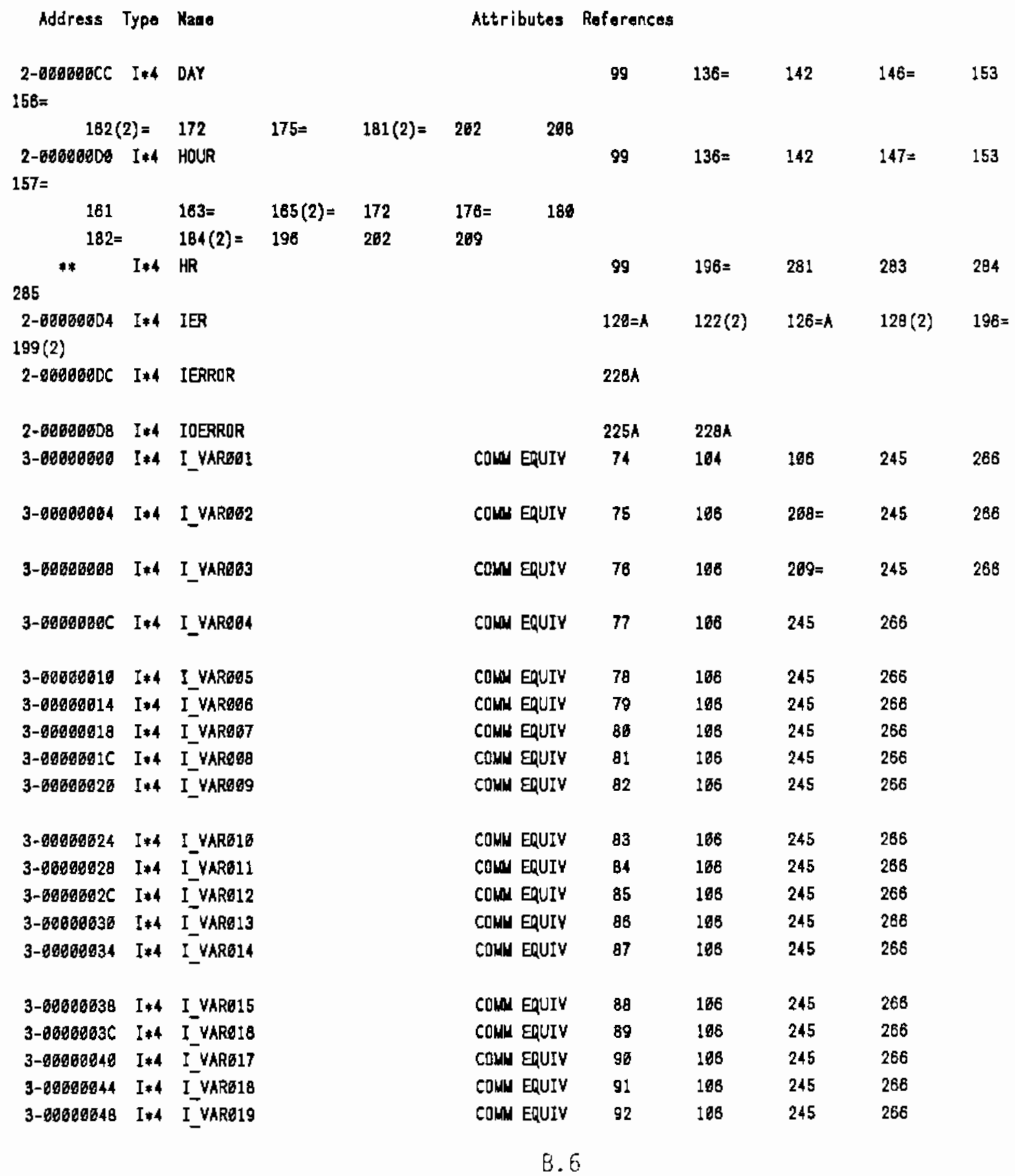




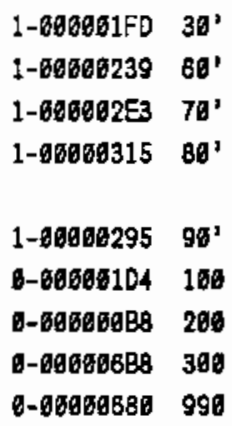

FUNCTIONS AND SUBROUTINES REFERNCE

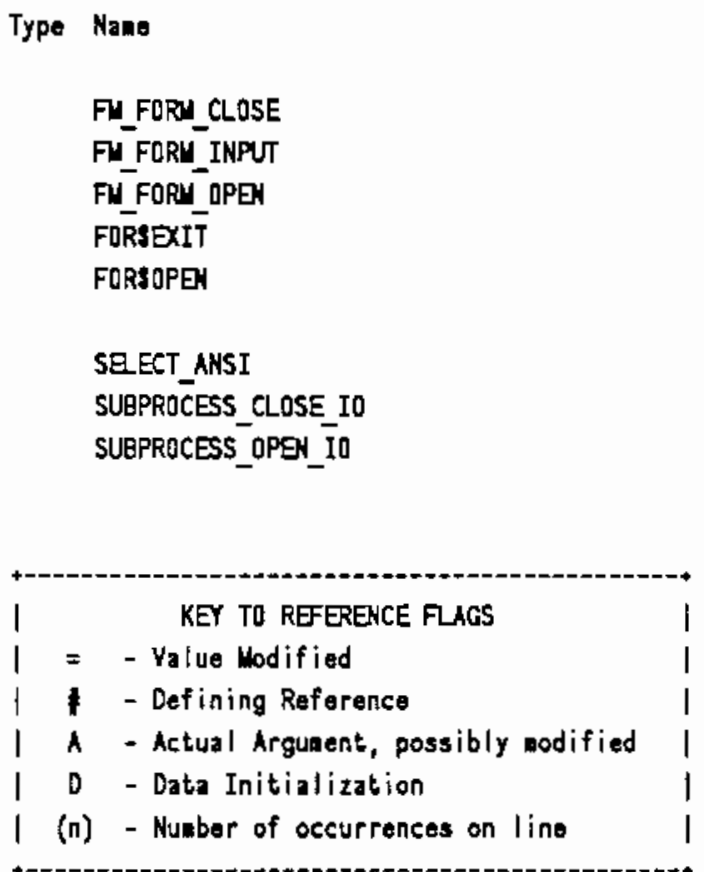

$\begin{array}{ll}128 & 129 \$ \\ 199 & 296 \$ \\ 245 & 251 \mid \\ 286 & 272 \\ & \\ 242 & 243 \mid \\ 223 \$ & 260 \\ 142 & 289 \\ 285 & 291 \\ 228 \AA & 293\end{array}$

Reforences

228

228

225

295

129

126

224

229

223

\section{COMUAND QUNIFIERS}

FOR/LIS/CROSS/CHECK=ALL SFC

/CHECK= (BQUNDS, OYERFL OW, UNDERFLOW)

/DEBUG = (NOSYMBOLS, TRACEACK)

/STANDARD= (NOSYNTAX, NOSOURCE_FORO)

/SHDT = (NOPREPROCESSOR, NOINCLUDE, WAP, NODICTIONARY, SINCE)

/TARNINCS= (GEYERAL, NDOECLARATIONS, NOURTRIX)

/CONTINUATIONS=19/CROSS_REFERENCE /NDD_LINES/NDEXTEND_SOURCE /F77 /NOG_FLOATING /I4 /NOMACHINE_CODE /OPTIMIZE

COMPILATION STAIISTICS
Run Time:
8. 29 seconds 
Elapsed Time: $\quad 11.87$ seconds

Page Faults: $\quad 755$

Dynamic Newory: 428 pages

B. 9 
, 


\section{DISTRIBUTION}

No. of

Copies

OFFSITE

2 DOE Technical Information Center

ONSITE

DOE Richland Operations Office

J. J. Sutey

29 Pacific Northwest Laboratory

G. L. Andrews (5)

K. A. Borgeson

J. W. Buck

D. W. Dragnich

O. P. Gifford

M. J. Graham

J. M. Hales

$P$. C. Hays

D. J. Hoitink

D. J. Newland

W. T. Pennell

P. J. Perrault

E. R. Preston

J. V. Ramsdell

G. N. Reinecke

M. N. Schwartz

L. L. Wende 11

R. E. Wildung

Publishing Coordination (2)

Technical Report Files (5) 
